\title{
VIDA MUNICIPAL EN LA REPUBLICA DE CHILE. EL SEGUNDO CONGRESO NACIONAL DE AL- CALDES. LA REFORMA COMUNAL
}

352(87)

por

\section{Carlos-Enrique Ruiz del Castillo y de Navascués}

Secretario Técnico del Centro de Cooperación Intermunicipal del Instituto de Estudios de Administración Local

SUMARIO: I. EL SEGUNDO CONGRESO NACIONAL DE ALCAL DES: 1. El marco. 2. Alocuctón del Presidente de la República. 3. INTERVENCION DEL MINISTRO DEL INTERIOR. 4. EXHORTACION DEl Ministro Secretario General del Gobierno. 5. Criterios del Ministro de Hacienda. 6. El Urbanismo. 7. El Documento «Estado y Municipio». 8. Clausura del Congreso. INTERvención DEL Ministro PResidente de CONARA.-II. LA REFORMA COMUNAL: 1. El CONTEXTO: CONARA. 2. LOS ENTES SUPRAMUNICIPALES: A) Los Entes regionales. B) Los Entes provinciales. 3. Los ENTES MUNICIPALES: A) Los Municipios. B) Valoración del nuevo sistema municipal. 4. La Region Metropolitana de Santiago.

\section{EL SEGUNDO CONGRESO NACIONAL DE ALCALDES}

1. El MARCo

Dentro de la vida política de la República de Chile, que ha emprendido una remodelación institucional y legal a partir del triunfo del Movimiento de Liberación Nacional, el 11 de septiembre de 1973, reviste gran importancia el deseo gubernamental de reestructurar y potenciar la vida municipal. El eco que la acción del Gobierno despierta ha movilizado por segunda vez a los Alcaldes de los Municipios chilenos, denominados Comunas en aquella Nación hermana. 
En efecto, la segunda quincena del mes de marzo último se inició con el Segundo Congreso Nacional de Alcaldes, cuya inauguración por el Presidente de la República, General don Augusto Pinochet, tuvo lugar en el edificio Diego Portales de la capital chilena, con asistencia del Ministro del Interior-quien habría de presidir la sesión de clausura del Congreso-, del Ministro Secretario General del Gobierno, del Ministro de Hacienda, del Ministro Director de la Oficina de Planificación Nacional (ODEPLAN) y del Ministro Presidente de la Comisión Nacional de Reforma Administrativa (CONARA), entre otras autoridades, así como de 286 Alcaldes, cifra muy importante si se considera que, según nuestro cómputo basado en las fuentes que tenemos disponibles, hay en Chile 315 Comunas con población superior a los 100 habitantes. Así, la participación activa en el Congreso de Alcaldes queda cifrada en más del noventa por ciento, lo que revela el interés ofrecido por esta convención, desde cualquier ángulo con que sea contemplada, y a la que el Gobierno ha prestado su máxima atención.

\section{Alocuctón del Presidente de la República}

En la sesión inaugural de este Segundo Congreso Nacional de Alcaldes de Chile, el Jefe del Estado subrayó que en la reforma política, social y económica emprendida por el Gobierno se ha querido y se ha tenido que contar con las Comunas y sus Alcaldes para aplicar el planeamiento a todo el territorio de la República, dado que dichas Entidades locales «son base fundamental de la participación y comunicación de la comunidad con las autoridades gubernativas». "Siempre he considerado al Municipio, habrá de decir el Presidente Pinochet, como el principal cuerpo social intermedio entre el hombre y el Estado, por estar basado en la realidad social más inmediata y concreta y constituir el lugar donde se manifiestan con claridad y nitidez las relaciones y los grupos humanos». «El $\mathrm{Mu}$. nicipio es la organización que responde al grupo y a la comunidad plena, de acuerdo con la naturaleza propia del ser humano, y, por tanto, constituye un factor de relación auténtica y directa con el Estado». Hizo referencia el General Pinochet al papel asignado a los Municipios en la Declaración de Principios (1) y atribuyó a los Al-

(1) Declaración de Principios del Gobierno de Chile, Editora Nacional Gabriela Mistral, Santiago de Chile, marzo de 1974. 
caldes el carácter de «ejes de la participación y de la comunicación», de forma que transmitan en doble corriente ascendente y descendente, los anhelos de los grupos y comunidades y las directrices del Gobierno inspiradas en el deseo de comunicar prosperidad y bienestar a unos y otras. Para ello el Estado necesita constituirse en organización fuerte, cuya fuerza la reciba de la propia cimentación social en las organizaciones sociales primarias constituidas por la familia, el sindicato y el Municipio. Así ha de llegarse al «Estado riguroso, ético y justo, servidor de un gran destino, es decir, de una Patria».

En esta andadura política, el Presidente incitó a que la acción acompañe a las palabras. Señaló el gran avance que ha significado la promulgación de la Ley de Rentas Municipales, pero apuntó también los vacíos que hay que colmar, como la redacción del Reglamento del Decreto-Ley 1289 que promulga la Ley Orgánica de las Municipalidades, la reestructuración de los servicios municipales y la ultimación del diseño de los nuevos Municipios salidos de la reorganización comunal. Para esa labor pide a los Alcaldes participación y apoyo, pues las metas fijadas sólo se podrán alcanzar desde las bases municipales hacia arriba: "Ustedes son esa base de apoyo al Gobierno-añadió el primer mandatario-y ustedes son mis representantes directos en cada Comuna: forman parte y son protagonistas de esta creación que es el nuevo Chile».

\section{INTERVENCIÓN DEL MINISTRO DEL INTERIOR}

El Ministro del Interior señaló en la sesión inaugural que el Gobierno aspira a «que los Municipios mejoren su organización y los Alcaldes mejoren su papel como instrumentos básicos de servicio a la comunidad y como canales insustituibles de participación de esta última». En este aspecto vituperó la vieja politización del Municipio, esterilizadora de esfuerzos y de estímulos que contribuyó a desfigurar su verdadera misión. A la Comuna corresponde una tarea creadora e integradora y no es pequeña la función-dentro de esa parcela-de constituirse en intermediaria entre el individuo y el Gobierno y de erigirse «en la célula básica de la participación ciudadana».

Dentro de ese espíritu, el Ministro del Interior entregó a los participantes en el Congreso un documento de trabajo elaborado bajo el título de «Estado y Municipio», al que más adelante se hará referencia. 
4. Exhortación del Ministro Secretario General del Gobierno

En la sesión de apertura de este Segundo Congreso Nacional de Alcaldes, el Ministro Secretario General del Gobierno abundó en la tesis del Municipio como empresa común, en la que han de comprometerse con sentido responsable, práctico y patriótico los gestores comunales y los administrados. Estos, por la vía de la participación social, vienen a ser coautores de los actos de gobierno de la cosa pública. Pero por ser necesario habilitar los cauces por los que se manifieste y discurra esa participación y por requerirse una coordinación de voluntades y de quehaceres, instó el Ministro a los Alcaldes a que la vida municipal encuentre la publicidad y el eco que necesita. Para ello subrayó la importancia de los noticiarios y los órganos escritos de difusión municipal y la conveniencia de reforzar «las entidades intermedias entre el hombre y el Estado, como las Juntas de vecinos, los centros de madres, los grupos juveniles y todo el voluntariado que trabaja por mística y que es la reserva más grande que posee la Patria».

\section{Criterios del Ministro de Hacienda}

La Ley de Rentas Municipales es el nuevo instrumento financiero y fiscal de la mayor utilidad para potenciar el Municipio chileno, dijo en su intervención el Ministro de Hacienda, quien glosó ante los Alcaldes aspectos fundamentales de la reciente ley inspirada, añadió, en la conveniencia de que, situada a mayor proximidad que el Estado ante los problemas de los núcleos comunitarios, sea la Comuna, en efecto, quien asuma la gestión de los servicios que den solución a aquéllos. Institucionalizadas de esta forma las prestaciones correspondientes, se habrá logrado mejorar la eficacia en la gestión, disminuir su coste y, por tanto, ahorrar fondos a los Municipios. Desde este punto de vista, cuando el Municipio justifique que puede operar con mayor eficacia que el Gobierno central en la gestión de un servicio determinado, éste será traspasado por el Estado a la Entidad municipal en unión de los recursos que para tal atención tuviera asignados el Gobierno. En conexión con ello, el Ministro hizo referencia al Fondo Municipal creado por la referida Ley de Rentas Municipales, que habrá de beneficiar a los Municipios que posean escasos recursos económicos y escasas posibilidades, también, para generar los que precisen sus responsabilidades de 
gestión de los servicios locales. De ahí, entre otras soluciones, ese traspaso de fondos del Estado a los Municipios, previsto en el artículo 88 de la Ley glosada, cuando dichos Entes locales asuman determinadas funciones que, como ha quedado dicho, les traspase el Estado previa justificación de la eficacia y el rendimiento que impriman a aquéllas.

El crecimiento económico de Chile, «a ritmo inusitado», es consecuencia, añadió, de la nueva filosofía en que se inspira la política chilena, y en relación con los Municipios, la gestión pública estará sólidamente anclada en los principios de libertad económica y de subsidiariedad. $\mathrm{Y}$ atendidos estos principios, instó a los Municipios a que "no invadan campos de acción en que pueda operar el sector privado", sector que es aconsejable sea llamado a desempeñar, cuando sea factible, labores directas de la competencia municipal.

\section{El URBANISMo}

Recoge esta crónica, por último, el tema de «Política económica y acción social del Gobierno», que desarrolló el Ministro Director de la Oficina de Planificación Nacional (ODEPLAN). El orador destacó de especial manera el sistema de subsidios para la construcción de viviendas y la redacción de un plan piloto para la vivienda rural, el cual va a ser iniciado con la distribución de 2.500 edificaciones entre los diversos Municipios chilenos. $Y$ en esta labor constructiva aludió el Ministro a la edificación de inmuebles con destino a servicios comunitarios de marcado interés social: correos, escuelas, policlínicas y hospitales. Para beneficiarse de las prestaciones que el Servicio de Seguro Social radique en tales edificios, a través del SERMENA, los beneficiarios verán aumentados los lugares de distribución de bonos-cheques en todos los Municipios de Chile.

\section{El Documento «Estado y Municipio»}

El documento de trabajo "Estado y Municipio», aludido más arriba, constituye la tesis del Gobierno chileno transmitida a los Alcaldes por el Ministro del Interior, basada en «los principios de sana descentralización y dispersión de los poderes», a través de una «división de funciones del Gobierno central y las municipalidades». A la luz de aquellos principios deben orientar los Alcaldes la política económica y social de sus respectivas comunidades. Porque esa división de funciones resulta «de vital importancia para la libertad, 
eficiencia y justicia de una sociedad». Se inicia así el documento, con una versión fiel del postulado de la Declaración de Principios del Gobierno, que se propone como objetivo final el resguardo de la libertad individual y el bien común, lo cual requiere la configuración de entidades $\mathrm{u}$ organizaciones privadas voluntarias y las organizaciones públicas como el Estado y los Municipios, al cual y a los cuales es de aplicación el principio de subsidiariedad.

Al desentrañar este principio de subsidiariedad, el documento alude a la necesidad que se planteó el Gobierno surgido del Movimiento Nacional de Liberación de 11 de septiembre de 1973, de revisar las verdaderas funciones del Estado, desvirtuadas por la práctica del poder constituido precedente. Después de hacer un breve examen histórico de la trayectoria reciente de Chile, concluye la precisa división de competencias estatales y municipales: «al Gobierno central le corresponden funciones que las municipalidades no alcanzan a cumplir, como son aquellos servicios que benefician a todos los habitantes del país: orden interno, relaciones exteriores, justicia, defensa nacional, etc. Pero, en el juego del principio de subsidiariedad, se limita la acción del Estado en lo demás a lo necesario, lo que permite afirmar, sin duda, que las personas, familias y organizaciones privadas de voluntariado son capaces por sí solas de perseguir sus propios fines y satisfacer plenamente muchas de sus necesidades». Dice en otro lugar el documento, que "queda un amplio ámbito de funciones para la Comuna, que es el resultante del quehacer total nacional, menos lo que le es propio e indelegable al Gobierno central y lo que por naturaleza corresponde a los individuos, la familia y organismos privados voluntarios».

El Gobierno central, continúa el documento, reconoce a la Co. muna como «cuerpo social intermedio eficiente y apropiado para el análisis y solución de muchos problemas». De la actuación de aquélla - detección y provisión de necesidades-surgen dos tipos de servicios que serán financiados de modo distinto, según el ámbito de su eficacia: con fondos generales y con fondos peculiares.

Todo ello obliga al Gobierno a formular tres compromisos: En primer lugar, es preciso dotar a los Municipios de fondos que les permitan financiar cierto tipo de servicios. En segundo lugar, hay que investir al Alcalde de responsabilidad y de facultades para que pueda llevar a cabo una gestión flexible y eficaz. Por último, el Gobierno se somete al principio de subsidiariedad y se compromete a que aquél se cumpla en todos sus extremos. 
$\mathrm{Y}$ una forma de completar esa acción y esa interdependencia que el mencionado principio comporta, consiste en la de estimular y vigilar la creación de órganos de expresión comunal, con lo que se vuelve a la idea de participación popular más arriba expuesta. Señala el documento, en este aspecto, los esfuerzos del Gobierno relativos a las Juntas de vecinos, a la Secretaría Nacional de la Mujer, a la Secretaría de la Juventud y a otro tipo de instituciones como los Cuerpos de Bomberos, las asociaciones deportivas, las agrupaciones filantrópicas y a cuantos canales de expresión pueden colaborar con las autoridades municipales a detectar aspiraciones y formular soluciones.

\section{Clausura del Congreso. Intervención del Ministro PRESIDENTE DE CONARA}

En la jornada de clausura de este Segundo Congreso Nacional de Alcaldes intervino el Ministro Presidente de la Comisión Nacional de Reforma Administrativa (CONARA). En su alocución a los Alcaldes subrayó el papel de célula fundamental que corresponde al Municipio, la inmediación de gestores y administrados que permite un contacto directo y la palpitación de la vida local con sus logros y sus carencias.

Las once medidas «que nos proponemos adoptar» para fortalecer el Municipio y hacer más eficaz la política social y económica del Estado, atenta al bien común, fueron enunciadas por el Ministro Presidente de CONARA con arreglo al siguiente esquema:

- Profunda modificación del actual régimen jurídico de las municipalidades, con normas flexibles, simples y claras que refuercen su acción directa ante la comunidad.

- Redefinición de las funciones municipales y clarificación de las esferas de poder central y local.

- Reestructuración de los servicios sobre la base de diferenciar los de estricta responsabilidad municipal, de los que requieran el apoyo nacional y de los de la exclusiva competencia de la Administración central.

- Atribuir a la autonomía municipal un sentido verídico y eficaz que permita el máximo de iniciativa, libertad de acción y de gerencia.

- Simplificar las estructuras municipales.

- Consolidar el rango jerárquico de Alcaldes y personal municipal con arreglo a las disponibilidades financieras. 
- Desvanecer los conflictos de competencias y atribuir, en la medida de lo posible, a las municipalidades los servicios de actual gestión nacional.

- Encomendar a las comunidades, a través de corporaciones privadas, convenios, etc., la prestación creciente de servicios que puedan atender con eficacia.

- Mejorar los organismos de participación, ensanchar su campo de acción, asegurar la continuidad de su labor y reordenar el Consejo Comunal, suprimiendo en él la integración funcionaria.

- En la misma línea, estimular el grado de participación de las organizaciones existentes en cada Municipio. Será restablecido, en este aspecto, el histórico cabildo abierto de las pequeñas entidades. de población.

- En los Municipios de mayor entidad demográfica serán potenciadas las unidades vecinales, con designación de delegados municipales como representantes directos y colaboradores del Alcalde.

Estos han sido los planteamientos del Segundo Congreso Nacional de Alcaldes de Chile. Una Nación que se ha puesto en pie, que trabaja y progresa y cuyo Gobierno hace de la participación palanca de la nueva institucionalidad. Subyace en todo ello el concepto de libertad ciudadana-como expuso en el Congreso el abogado don Jaime Guzmán-para el impulso de una sociedad en la cual el pueblo es, en definitiva, el que toma las grandes decisiones gracias al impulso vital del "ser humano dotado de espiritualidad», como quiso subrayar el Presidente chileno.

\section{LA REFORMA COMUNAL}

\section{El CONTEXTO: CONARA}

El análisis de la normativa y de las correspondientes instituciones. vigentes el 11 de septiembre de 1973, constituían materia acuciante para la Honorable Junta de Gobierno. Era preciso adecuar una y otras a la nueva filosofía política y era urgente sentar las bases de la nueva organización de la convivencia y del impulso vital para ese nuevo Chile. Hubo de constituirse, pues, una Comisión preliminar de la Reforma Administrativa integrada por militares y expertos civiles 
de la Administración Central, de las Universidades y del sector privado. El trabajo de la Comisión cuajó en un informe titulado «Diagnóstico de la Administración Pública Chilena» (2), con el siguiente contenido: 1. Deficiencias estructurales: a) Falta de uniformidad y organicidad en el desarrollo institucional del sector público. b) Proliferación de entes o servicios autónomos. c) Existencia de una verdadera Administración pública invisible. d) Superposición de estructuras institucionales y duplicación de funciones. e) Falta de coordinación entre estructuras diferenciadas. f) Incongruencia entre criterios básicos de la planificación y el ordenamiento administrativo, especialmente acerca de la regionalización. h) Excesiva complejidad de las estructuras internas de Ministerios y servicios. 2. Deficiencias de planificación: a) Carencia de una organización integral del sistema de planificación. b) Inexistencia de una efectiva organización de la planificación sectorial, regional y local. c) Desvinculación entre planificación y asignación de recursos financieros. 3. Uso inadecuado de los recursos: a) Recursos humanos: inexistencia de un sistema idóneo de su planificación. Inexistencia de un sistema de formación y desarrollo de los recursos humanos de la Administración pública. Deficiente sistema de Administración del funcionariado de carrera. b) Recursos financieros. c) Recursos materiales. 4. Complejidad de los sistemas y procedimientos de trabajo: falta de «métodos y procedimientos» de trabajo en la Administración pública. Falta de normas que impongan un procedimiento administrativo eficiente y uniforme. Incertidumbre e indefensión permanentes de los administrados. 5. Infrautilización y falta de desarrollo de los sistemas de informática. 6. Sistemas de control inadecuados.

El Informe señala que los objetivos deben ser alcanzados, según su respectiva naturaleza, por una reforma que operará gradual y constantemente en plazos que tendrán carácter inmediato, medio (cinco años) y largo (permanentemente). Y considerado este documento por la Junta de Gobierno de la República de Chile, se decidió ésta a promulgar el Decreto-Ley 212, de 17 de diciembre de 1973, que crea la Comisión Nacional de la Reforma Administrativa (CONARA), a la que el artículo $1 .^{\circ}$ atribuye las más amplias funciones para acometer la reforma administrativa propugnada en el Informe. Para ello, queda investida de facultades de ejecución, coordinación, vigi-

(2) Chile hacia un nuevo Destino: su Reforma Administrativa integral y el Proceso de Regionalización. Comisión Nacional de la Reforma Administrativa, CONARA. Documento núm. 2. Talleres de la Editora Nacional Gabriela Mistral, Ltda. Santiago, junio 1976, págs. 29 y ss. 
lancia, información, estudio, asesoramiento y elevación de propuestas a la Junta de Gobierno.

La Comisión Nacional de la Reforma Administrativa (CONARA) queda situada bajo la dependencia directa de la Junta de Gobierno, y su presidente (Oficial superior de los Cuerpos Armados) será designado por Decreto supremo. Su estructura interna consta de un Comité Coordinador y su Secretaría Ejecutiva, una Comisión Consultiva y Subcomisiones de Trabajo. El Comité Coordinador será presidido por el propio presidente de CONARA y se compondrá, además de un representante del Ministerio del Interior, designado por éste, de cinco miembros de los Cuerpos Armados, nombrados por Decreto supremo a propuesta del presidente de CONARA y por un máximo de seis profesionales especialistas de la Administración pública, nombrados también por Decreto supremo y bajo igual tipo de propuesta. La Comisión Consultiva comprenderá representantes de los Ministerios, de los Servicios públicos, Universidades, organizaciones sociales y entidades técnicas o especializadas, según requiera el Comité Coordinador con arreglo a la naturaleza de las materias. en que deba entender. Las Subcomisiones de Trabajo, por último, serán fijadas y organizadas por el Comité Coordinador, al que corresponde asignarles las tareas específicas y, en su virtud, las funciones y atribuciones que requiera el mejor desempeño de su cometido.

El Decreto-Ley prevé, finalmente, la necesidad de facilitar el trabajo de CONARA situándola en condiciones óptimas de conocimiento en extensión y profundidad de las variables que se entrecruzan en cualquier tema cuyo estudio y solución acometa. Para ello, quedan obligados todos los Servicios del Estado, las oficinas autónomas, las. municipalidades y sus servicios y toda persona jurídica estatal, local o privada, a presentar a CONARA, cuando fuesen requeridos a ello, cuantos informes y antecedentes puedan mejorar el conocimiento de los problemas y, asimismo, deberán prestar a dicha Comisión toda la colaboración técnica y administrativa que aquélla les solicite. $\mathrm{Y}$ cuantas Comisiones creadas o por crear, se propongan conocer o resolver sobre aspectos relacionados con reformas administrativas generales o especiales, quedan igualmente obligadas a someter sus propuestas o resoluciones a CONARA.

Y así es como inició dicha Comisión sus trabajos sobre la reforma administrativa, para la que proyectó cuatro fases relativas a la 
regionalización, a la provincialización, a los Municipios y a la Región Metropolitana de Santiago. A continuación quedan bosquejados los principales rasgos de estas cuatro direcciones de la reforma.

\section{LOS ENTES SUPRAMUNICIPALES}

\section{A) Los Entes regionales}

Los estudios precisos para la Reforma Regional encomendados a la Comisión Nacional de la Reforma Administrativa (CONARA), contaron con la colaboración de la Comisión de Reforma Constitucional y las Comunidades afectadas por las reformas, con lo que CONARA vino a completar una serie de propuestas, aceptadas por el Gobierno, que constituyeron la primera fase de su tarea institucional al servicio de la renovación de Chile.

Con la Regionalización se produce un "cambio histórico y trascendental en las estructuras del país», en palabras del Presidente de la República, General don Augusto Pinochet, quien para explicar el proceso llevado a cabo considera preciso «señalar claramente que el Estado de Chile es unitario, donde el poder político, en la plenitud de sus atribuciones y de sus funciones, lo sirve una misma Autoridad Nacional y bajo un mismo régimen jurídico. Sin perjuicio de la plena vigencia de ello, la modernización del Estado de Chile, por sus peculiares condiciones geográficas, requiere un sistema que permita un desarrollo descentralizado administrativa y regionalmente, para que se materialice en la forma más perfecta posible la coordinación y la participación de las Regiones en función de la Integración, la Seguridad, el Desarrollo Socioeconómico y la Administración Nacional» (3).

Y resultó de esa primera fase de remodelación político-administrativa estudiada por CONARA el Decreto-Ley 575, de 10 de julio de 1974, por el que la Honorable Junta de Gobierno daba lugar al nacimiento de 12 Regiones-en sustitución de los antiguos Departamentos que agrupaban las 25 Provincias en que se dividía Chiley la Región Metropolitana de Santiago, a la vez que definía el sistema administrativo de los nuevos Entes regionales. Regiones, que con arreglo a las denominaciones propuestas por CONARA pasan

(3) Del Manifiesto de S. E. el Presidente de la República, General del Ejército don Augusto Pinochet Ugarte, con motivo de la iniciación del proceso de regionalización del país, Santiago de Chile, 11-7-1974. Documento núm. 2 de CONARA, ya citado. 
a denominarse: Tarapaca (2), Antofagasta (3), Atacama (3), Coquimbo (3), Aconcagua (5), Libertador General Bernardo O'Higgings (2), Maule (3), Biobío (4), La Araucana (2), Los Lagos (5), Aisén del General Carlos Ibáñez del Campo (3), Magallanes y Antártica Chilena (4), y la Región Metropolitana de Santiago (2). Figura entre paréntesis el número de Provincias de cada Región.

La característica de la Administración regional consiste en ser un sistema de descentralización y desconcentración en lo operativo y funcional. Con la primera se obtiene el traspaso de iniciativa y participación desde el Poder central, tanto a las autoridades regionales (el Intendente de la Región es la primera de ellas) y a las provinciales o microrregionales (hay un Gobernador al frente de cada Provincia), como a órganos descentralizados, que es el caso de las municipalidades, y a órganos consultivos y eventualmente decisorios de participación social, tales como los Consejos Regionales de Desarrollo, Consejos Comunales de Desarrollo, etc. Con la desconcentración habrá de lograrse el traspaso de facultades de los órganos centrales a las autoridades regionales o a los órganos de representación de los servicios públicos, empresas públicas y entes autónomos, de forma que el ejercicio del poder delegado permita y facilite la solución de los problemas locales.

\section{B) Los Entes provinciales}

La segunda fase de la reforma consistía en la remodelación provincial. Fase cuya preparación coexistía con la anterior; es decir, que no hubo prelación temporal puesto que, entre otras razones, las materias tratadas por las respectivas Comisiones de estudio de CONARA eran interdependientes. Atribuido a la Provincia el carácter de microrregión, CONARA define a ésta como «un ámbito geográfico con un destino productivo característico y predominante, dentro del cual existe una estructuración de entidades de población jerarquizadas e intercomunicadas con su Centro Urbano principal, mediante un sistema vial concurrente a éste, sistema vial que funciona dentro de un óptimo de distancia-tiempo, en consideración de la frecuencia de las actividades habituales de la población y, particularmente, en relación con el equipamiento urbano». Así, entre Región y microrregión, añade CONARA, «no hay, por tanto, una simple diferencia de tamaño, no se trata del mismo elemento territorial visto en dos escalas. Las diferencias entre ambas son básicas y de sus respectivos contenidos se deduce que: la microrregión debe 
desarrollarse intensificando su producción típica; en cambio, la Región lo hará sobre la base de integrar diversos sectores de la producción, representados por las microrregiones".

Con estos criterios han quedado configuradas 41 Provincias repartidas por las 13 Regiones chilenas y entre aquéllas quedan computadas el Gran Santiago y el resto de su Región Metropolitana. Así ha quedado dispuesto por el Decreto-Ley 1230, de 4 de noviembre de 1974, para la división provincial de las Regiones piloto y por el Decreto-Ley 1317, de 31 de diciembre de 1975, para la de las Regiones no piloto.

\section{Los ENTES MUNicipales}

\section{A) Los Municipios}

El estudio por CONARA de la tercera fase de la reorganización político-administrativa de Chile, dedicado a la reestructuración municipal fue, asimismo, simultáneo con los de las dos fases anteriores ya comentadas. Por una parte, fue preparada una nueva ley de atribuciones y organizaciones de las municipalidades, sobre la base de un estudio elaborado por una Subcomisión del Ministerio del Interior. Esta fue la génesis de la Ley Orgánica de Municipios y Administración Comunal, dictada por Decreto-Ley 1289, de 14 de enero de 1976. Por otra parte, se trataba de remodelar los límites comunales mediantè un prolijo trabajo de CONARA, quien formulará las correspondientes propuestas al Gobierno sobre la base de estudios y propuestas de las autoridades provinciales con consulta a las comunas afectadas. Se trata de dejar bien sentadas las esferas competenciales y de anudar los lazos de interdependencia precisos.

A este respecto, el Presidente de la República indicó en su Manifiesto que interesa particularmente este nivel comunal, porque tanto en él como en el regional es donde naturalmente se ofrecen las mejores y más profundas oportunidades para la participación y el desarrollo social. Se establece, así, un sistema que reconoce niveles que garanticen eficiencia y responsabilidad en el ejercicio del poder, permite la participación organizada de la comunidad en cada nivel y facilita la planificación y administración del proceso regional (4).

Añade el Informe de CONARA, que se ha estimado fundamental

(4) Vid. Documento núm. 2 de CONARA, ya citado, pág. 13. 
por parte de ésta mantener el principio de que las municipalidades son instituciones de derecho público, funcional y territorialmente descentralizadas, para satisfacer las necesidades de la comunidad local y participar en la planificación y ejecución del desarrollo económico y social de la Comuna, bien por su acción directa, bien coordinando su gestión con la de otros Municipios, servicios públicos y organizaciones del sector privado. Pero no entiende por ello CONARA que la municipalidad sea un simple servicio público, ya que va a constituirse en medio de expresión de la comunidad local; y para que esa voz local sea auténtica y logre la proyección que le corresponde en el campo jurídico e institucional, necesita cierta autonomía y personalidad propias.

Facultades originarias y privativas de las municipalidades son, con criterios de CONARA, la elaboración y fiscalización de los planes de desarrollo local, la administración de bienes nacionales de uso público existentes en la Comuna y de interés exclusivamente local, el tráfico dentro de aquélla, su ornato y limpieza y las normas de construcción y urbanización en su demarcación, sin perjuicio de la supervisión que a otros organismos corresponda. Las demás atribuciones de las municipalidades serán determinadas por ley.

Las Comunas quedan estructuradas bajo la gestión de las municipalidades, a cuyo frente habrá un Alcalde designado por el titular del Poder ejecutivo, previa consulta al Intendente regional. Dicho Alcalde, con amplias potestades de resolución de los problemas locales, será asesorado por un Consejo de Desarrollo Comunal, elemento básico de la nueva estructura municipal, a través del cual la comunidad local podrá expresar sus criterios sobre las cuestiones vecinales y sobre el desarrollo de la Comuna. Esta es la razón de que en cada municipalidad exista un Consejo de Desarrollo Comunal presidido por el Alcalde e integrado por los Jefes de las Oficinas municipales, representantes de las Juntas de vecinos y portavoces de otras actividades, organismos e instituciones privadas de la Comuna. A ese Consejo corresponden las facultades decisorias y consultivas que la ley señale y participará primordialmente en la aprobación de las políticas, planes y programas de desarrollo comunal.

En relación con ello, la Comisión de Estudio de CONARA estimó oportuno mantener las Oficinas Locales de Coordinación y Planificación como órgano asesor y secretaría técnica de los Alcaldes y de los Consejos de Desarrollo Comunal. Las Oficinas mencionadas podrán asesorar a una o a varias municipalidades. 
Y para la mayor eficacia del desarrollo comunal dispone la ley la participación de las municipalidades en la asignación de los recursos públicos, con independencia de dotarlas de facultades suficientes para la administración financiera.

\section{B) Valoración del nuevo sistema municipal}

A través del Decreto-Ley 1289, el Municipio, carente hasta entonces de importancia en el proceso del impulso regional, adquiere importancia señera en el desarrollo físico y social de la Región. La comunidad local adquiere protagonismo a través de la participación encauzada e institucionalizada. La independencia municipal respecto de la Administración del Estado se convierte en una autonomía operativa dentro de su participación activa en la gestión general del Estado, configurada como un Servicio público. El nuevo Municipio ya no es un organismo político de carácter pasivo: tiene ahora una misión activa de participación en el impulso del desarrollo local, mediante la gestión de un nivel de planificación eminentemente técnico. El Alcalde, Jefe del Municipio que sin potestades de mando reglamentarias y ejecutivas veía diluida su responsabilidad, cubre hoy con tales potestades una mayor esfera de competencias, responde directamente de la gestión municipal y coopera con el Estado en la gestión de otros servicios con que éste beneficia a la comunidad local. Los funcionarios municipales quedan acogidos al Estatuto de los funcionarios públicos, suprimido su régimen especial. La nueva tipología comunal recibe un tratamiento diferenciado, con lo que desaparece el tratamiento uniforme de Municipios diferentes y la planificación provincial ejerce una acción sustitutoria en relación con la comunal; los Municipios rurales adquieren una organización y tratamiento peculiares. El Gobernador provincial refuerza con su tutela la amplia autonomía operativa de los Municipios en las materias de su exclusiva competencia, a través de la integración del régimen municipal en el sistema administrativo provincial y regional. El principio de subsidiariedad es llevado a sus máximas posibilidades y queda jerarquizada, en fin, una actividad pública vinculada desde el Municipio hasta el Estado, con lazos interdependientes pero respetuosos con lo privativo de cada nivel administrativo.

\section{La Región Metropolitana de Santiago}

Como caso particular y digno de la mayor atención en la nueva división regional de la República de Chile, CONARA hubo de con- 
templar la conurbación de Santiago y su esfera de influencia, lo que le llevó a crear en su seno una Subcomisión que daría un tratamiento aislado a esta cuestión. En efecto, ella sola integró la cuarta fase de la Reforma Política y Administrativa, con el resultado de crear una XIII Región: la Región Metropolitana de Santiago, después de estudios y trabajos paralelos a los dedicados por CONARA a las tres fases anteriormente descritas.

Sobran razones para este tratamiento especial de la Región Metropolitana de Santiago. La población, de 3,8 millones de habitantes en 31 de diciembre de 1975, está asentada en casi 14.000 kilómetros cuadrados. Dicho de otro modo, el 37 por ciento de la población nacional arroja para ese pequeño territorio una densidad de 278,5 habitantes por kilómetro cuadrado, lo que significa una densidad que guarda enorme desproporción con la del resto de Chile. Por otra parte, que Santiago albergue la capitalidad de la Nación y los servicios centrales de su Administración supone también un cúmulo de razones que exigen un tratamiento especial de la Región. En el orden económico-comercial, Santiago enlaza el norte minero con el sur agrícola y comercial y resulta, así, encrucijada de caminos, de relaciones, de flujos humanos, monetarios y de bienes, con lo que se ha convertido en un núcleo, alma y nervio de toda la Nación. Ello ha creado una concentración humana de la que deriva la exigencia de dar adecuado tratamiento a los temas urbanísticos, económicos, comerciales, industriales y sociales que el hecho suscita (5).

En vista de todo ello, CONARA propuso la división de la Región Metropolitana de Santiago en dos Provincias: Gran Santiago y Resto de la Región; en 17 Municipios la primera y 16 la segunda. El informe de CONARA consideraba la conveniencia de dotar a la Región Metropolitana de un sistema de gobierno con capacidad de autogestión-respecto del régimen de Gobierno Central Nacional-así como la necesidad de proceder a su inmediata puesta en marcha, por etapas, a partir de la promulgación del Decreto-Ley correspondiente.

Elaboraciones posteriores a esos estudios han dado lugar al Decreto-Ley 3260, que ha entrado en vigor en abril de 1980 (6), en virtud del cual, la Región Metropolitana de Santiago queda dividida

(5) Para descongestionar la Región se va a llevar una política fiscal de penalización por radicación de industrias en la Región y de subsidios y primas por su traslado a otros lugares de Chile.

(6) El Mercurio de Chile, Santiago de Chile, semana del 24 al 39 de abril de 1980 , página 6. 
en un Area Metropolitana con 3.561 .000 habitantes y cinco Provincias que reúnen otros 665.500 , con lo que la Región engloba una población de 4.226 .000 almas.

El Area Metropolitana de Santiago es un conjunto de 15 Municipios sin solución de continuidad en sus calles y edificaciones: Santiago, la capital, con 317.361 habitantes, Las Condes, Providencia, La Reina, Nuñoa, La Florida, San Miguel, La Granja, La Cisterna, Maipú, Quinta Normal, Pudahuel, Renca, Quilicura y Conchalí, el menor de todos los Municipios señalados, con 40.045 habitantes, frente a los 417.064 del mayor: Nuñoa. La población media de cada Municipio es de 237.382 almas.

Las cinco Provincias que componen el resto de la Región Metropolitana son Chacabuco, con 50.106 habitantes en tres Municipios, capital Colina (24.962); Cordillera, con 135.583 almas en otros tres Municipios, capital Puente Alto (117.243); Maipo, con 269.595 habitantes en cuatro Municipios, capital San Bernardo (200.722); Talagante, con 116.969 almas en otros cuatro Municipios, capital Talagante (27.726), y Melipilla, con 93.314 almas en cinco Municipios, capital Melipilla (61.922), con el Municipio de menor población de toda la Región Metropolitana de Santiago: Alhué, con 4.563 habitantes.

El gobierno y administración de toda la Región Metropolitana queda confiado, por el Decreto 3260, a un Intendente Regional Metropolitano, que será designado por el Presidente de la República, y a quien corresponderá, además, coordinar la actuación de los organismos metropolitanos, la de los Municipios relativa a transporte y tráfico, la preservación del medio ambiente y la supervisión del cumplimiento de las medidas acordadas dentro de la Región o dictadas por ésta. Por otra parte, el Intendente Regional acumula las funciones de Gobernador Provincial del Area Metropolitana. En su calidad de Intendente puede delegar sus funciones en los Gobernadores provinciales, en los Alcaldes o en cualquier otra autoridad de la Región. Tanto la Intendencia Regional como los Gobiernos provinciales o los Municipios de la Región serán organizados, estructurados y dotados de personal funcionario por el Presidente de la República, en el plazo de un año a partir de la publicación del Decreto, según establecen sus disposiciones transitorias. El actual personal que quede sin destino será automáticamente jubilado.

De la misma forma procederá el Presidente con la Secretaría Regional de Planificación y Coordinación Metropolitana, creada por el propio Decreto y dependiente de la Intendencia Regional, a la que 
quedan igualmente subordinados los Gobernadores provinciales y los Alcaldes de los Municipios de su jurisdicción. Estos formarán, por otra parte, un Comité asesor para asistir al Intendente en todo cuanto fueran requeridos.

Se espera que del Decreto 3260 deriven para Santiago soluciones adecuadas a los problemas metropolitanos, señaladamente el del tráfico y, dentro de éste, el del estacionamiento de los 18.000 vehículos que ocupan la vialidad santiaguesa, incluso con invasión de aceras y espacios verdes. $Y$ dado que a primero de septiembre de 1981 quedarán suprimidas las áreas de estacionamiento del centro de la ciudad, el Municipio ha acometido la construcción de un edificio destinado a albergar 900 vehículos. Representa una inversión de cuatro millones de dólares (7) y 14.000 metros cuadrados edificados. A esta obra, que finalizará con el presente año de 1980, seguirán otras del mismo tipo. Están dando ocupación a 450 obreros.

En otro orden de cosas y dadas las dificultades financieras de la Corporación, los gestores de Santiago han dado con una fórmula que se viene aplicando con éxito: cada proyecto se procura financiar con la mínima contribución de la municipalidad y con la mayor aportación posible de los vecinos. Se trata de un sistema de cooperación loable y eficaz que ha hecho posible, por ejemplo, la construcción de los paseos de Ahumada y Huérfanos, financiados por los comerciantes de esas vías casi en un 100 por 100. Cabe citar, también, la construcción del edificio comercial de seis plantas «Bandera-Centro" como primera aportación privada a la remodelación del «Paseo Catedral». La municipalidad, en una ambiciosa tarea de urbanización, estimula en lo posible estas cooperaciones y proyecta reordenaciones como la de la Plaza de Armas y la calle de San Diego.

No llega a más esta mirada rápida por el amplio temario expuesto. El cronista tiene que apelar a la benevolencia del lector por las omisiones y deficiencias que, en parte, son hijas del escaso material de que ha dispuesto para el trazado de esta panorámica sobre la reciente organización de la Administración local de la hermana Nación chilena.

(7) Unos 300 millones de pesetas. 
REVISTA

DE

ESTUDIOS

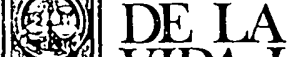

- VIIDA LOCAL

\section{ESTADISTICA}

REVL-1980, núm. 206. RUIZ DEL CASTILLO Y DE NAVASCUES, CARLOS ENRIQUE. VIDA MUNI... 
REVL-1980, núm. 206. RUIZ DEL CASTILLO Y DE NAVASCUES, CARLOS ENRIQUE. VIDA MUNI...

REVL-1980, núm. 206. RUIZ DEL CASTILLO Y DE NAVASCUES, CARLOS ENRIQUE. VIDA MUNI... 